http://dx.doi.org/10.1590/0104-1428.1938

\title{
Thermal Stabilization study of polyacrylonitrile fiber obtained by extrusion
}

\author{
Robson Fleming Ribeiro ${ }^{1 *}$, Luiz Claudio Pardini², Nilton Pereira Alves ${ }^{3}$ and Carlos Alberto Rios Brito Júnior \\ 'Departamento de Química, Instituto Tecnológico de Aeronáutica - ITA, São José dos Campos, SP, Brazil \\ ${ }^{2}$ Departamento de Ciência e Tecnologia Aeroespacial, Instituto de Aeronáutica e Espaço, \\ Instituto Tecnológico de Aeronáutica - ITA, São José dos Campos, SP, Brazil \\ ${ }^{3}$ Quimlab Científica Ltda, Jacareí, SP, Brazil \\ ${ }^{4}$ Universidade Federal do Maranhão - UFMA, São Luís, MA, Brazil \\ *robsonfleming@gmail.com
}

\begin{abstract}
A low cost and environmental friendly extrusion process of the Polyacrylonitrile (PAN) polymer was viabilized by using the 1,2,3-propanetriol (glycerol) as a plasticizer. The characterization of the fibers obtained by this process was the object of study in the present work. The PAN fibers were heat treated in the range of $200{ }^{\circ} \mathrm{C}$ to $300{ }^{\circ} \mathrm{C}$, which is the temperature range related to the stabilization/oxidation step. This is a limiting phase during the carbon fiber processing. The characterization of the fibers was made using infrared spectroscopy, thermal analysis and microscopy. TGA revealed that the degradation of the extruded PAN co-VA fibers between $250{ }^{\circ} \mathrm{C}$ and $350{ }^{\circ} \mathrm{C}$, corresponded to a $9 \%$ weight loss to samples analyzed under oxidizing atmosphere and $18 \%$ when the samples were analyzed under inert atmosphere. DSC showed that the exothermic reactions on the extruded PAN co-VA fibers under oxidizing synthetic air was broader and the cyclization started at a lower temperature compared under inert atmosphere. Furthermore, FT-IR analysis correlated with thermal anlysis showed that the stabilization/oxidation process of the extruded PAN fiber were coherent with other works that used PAN fibers obtained by other spinning processes.
\end{abstract}

Keywords: polyacrylonitrile fibers, extrusion process, stabilization process, carbon fibers.

\section{Introduction}

Polyacrylonitrile (PAN) fibers have been the most used precursor for carbon fibers manufacture. Nowadays, PAN fiber represents about $90 \%$ of worldwide carbon fiber production. The production of PAN fibers, commercially in the form of copolymers, for over 50 years has been performed by wet spinning and dry spinning processes ${ }^{[1,2]}$. These processes are based on the use of organic solvents that dissolve the PAN polymer and a solution is formed. The solution is then pumped through a spinneret having a multiplicity of tiny holes ${ }^{[1,2]}$. The solution used in a wet spinning process usually consists of 10 to $30 \%$ by weight of PAN dissolved in a polar solvent, such as dimethylformamide (DMF), dimethysulfoxide (DMSO) or dimethylacetamide (DMAc) ${ }^{[3,4]}$. Although PAN fibers can be produced by either wet or dry spinning processes, wet spinning is used to produce nearly all commercial aerospace grade PAN-based carbon fibers.

Due to the large amounts of solvents used and consequently environmental concerns, PAN industrial plants needs a solvent recovery plant. This contributes to an increase in PAN fiber final cost, which nowadays corresponds to nearly $50 \%$ of the carbon fiber final cost ( $\sim$ US\$ 50.00/kg). So, carbon fiber uses are still concentrated only in areas where the importance of material performance overlaps the drawbacks of relative high cost production. However, the development of new processes without the use of toxic and high cost solvents, it could become an attractive technology route for PAN polymers. Several attempts have been made along the years to process PAN by using conventional thermoplastic extrusion technology. In this way, some processes were patented, mainly from BASF and Dupont, but they were not commercially viable because the need for water at high temperature $\left(200{ }^{\circ} \mathrm{C}\right)$ as a melt carrier ${ }^{[5-7]}$. Besides, the extrusion process has to be accomplished at high pressure (3-7 MPa), and, as a consequence, robust equipment was needed for continuous extrusion.

Others attempts have been made trying to obtain meltable PAN copolymers for fiber manufacture, which were later patented under trade names of Barex and Amilon ${ }^{[8,9]}$. In this case, the acrylonitrile polymerization was done by emulsion and the high cost of comonomers has threatened the economic viability of the products. Bortner ${ }^{[10]}$, for instance, demonstrated successfully that using supercritical carbon dioxide as a plasticizer for PAN, which reduces the glass transition temperature and lead to a reduction in the PAN melting point, avoiding PAN degradation. In this case, PAN could be processed by injection, but the process has to be carried out at high pressure $(6 \mathrm{MPa})$ with liquid $\mathrm{CO}_{2}$, in a pressure vessel $(17.2 \mathrm{MPa})$, at $120^{\circ} \mathrm{C}$, to accomplish the saturation with acrylonitrile.

PAN copolymers could also be processed by extrusion by using 1,2,3-propanetriol (glycerol) as a plasticizer ${ }^{[11]}$. The 1,2,3-propanetriol has a high boiling point $\left(\sim 290^{\circ} \mathrm{C}\right)$ and exhibits high miscibility with PAN, due to the three hydroxyl groups in its backbone which provides a polar nature substance. Thus, these groups interact with nitrile group and can delay the PAN nitrile group's cyclization ${ }^{[11]}$. 
Thus, the PAN polymer melt before crosslinking and suppresses the exothermic reactions related to the cyclization reactions which takes place over $200^{\circ} \mathrm{C}$. In that way, PAN fibers can be spun by using conventional extrusion process (melt spinning ${ }^{[4,12]}$. In relation to acrylic fiber production this approach can lead to a substantial cost reduction in relation to the traditional wet and dry spinning processes ${ }^{[1]}$. Besides, it is environmentally friendly since avoids human exposure to toxic solvents. Also, the use of glycerol as PAN plasticizer on industrial scale becomes an alternative route for using glycerin produced by biodiesel industry waste.

Conversion of PAN fibers to carbon fibers requires a critical thermal stabilization stage which has great influence on the final properties of the carbon fibers. The stabilization process is commonly performed in air between 200 and $300{ }^{\circ} \mathrm{C}^{[13,14]}$. During this process, PAN undergoes a number of physical and chemical changes which converts the linear PAN molecular chains to an aromatic ladder structure suitable for further heat treatment (carbonization) and conversion to carbon fibers. Although the chemistry of stabilization process is complex, this stage consists basically of exothermic chemical reactions, including cyclization of nitrile groups, dehydrogenation, oxidation and crosslinking among the polymer chains ${ }^{[15,16]}$.

Several mechanisms have been proposed to explain the structure of PAN fiber backbone and its stabilization oxidative process. Fourier transform infrared (FT-IR) spectroscopy, microscopy and thermal analysis have proven to be excellent techniques to study the structural evolution of PAN fibers during the stabilization. In this work, PAN fibers spun by the extrusion process were submitted to heat treatment processes, related to stabilization stage. The main functional groups and thermal behavior of extruder PAN fibers were identified and characterized. Results were compared with the PAN fibers spun from conventional solvent wet and dry spinning processes.

\section{Experimental}

\subsection{Materials}

Extruded PAN fibers were obtained by continuous extrusion process. In order to obtain PAN fibers, a PAN copolymer having 94\%/mass of acrylonitrile monomer (AN) and $6 \% /$ mass of vinyl acetate (VA) was used. The PAN co-VA was provided by Radicifibras (Brazil/SP) having a number average molecular weight $\left(\mathrm{M}_{\mathrm{n}}\right)$ of $45000 \mathrm{~g} / \mathrm{mol}$. The glycerol was provided by Vetec Química (Brazil) having $99.5 \%$ purity, $M_{n}$ of $92 \mathrm{~g} / \mathrm{mol}$, melting point at $\sim 18{ }^{\circ} \mathrm{C}$ and boiling point at $\sim 290^{\circ} \mathrm{C}$.

\subsection{Melt spinning process for PAN fibers}

The process of melt spinning of PAN $\mathrm{co}$-VA fibers is based in two stages. The first step corresponds to the formation of pellets of PAN plasticized with glycerol by a single screw extrusion and formation of PAN fiber by cascade extruder equipment. The compound is prepared by mixing $70 \% /$ mass of PAN co-VA powder, $28 \%$ /mass of glycerol and $2 \%$ /mass of glycol additives ${ }^{[11]}$. The pre-extrusion compound is homogenized and put into the hopper extruder equipment. Figure 1 shows a schematic view for PAN fibers extrusion. Afterwards, the compound melts at 200 and $220^{\circ} \mathrm{C}$ and it is transported by a single screw through the barrel. The molten polymer is compressed up through a circular die duct of $6 \mathrm{~mm}$ diameter and the compound has been conformed into filaments. The filaments are then pulled and stretched reducing its cross section to a diameter of up to $3 \mathrm{~mm}$. Further, the $3 \mathrm{~mm}$ filaments are cut by a rotary knife turning it into pellets of plasticized PAN.

The second step is concerned with extrusion of PAN pellets for obtaining fibers. The Figure 2 shows a schematic view of the cascade extruder equipment used in this stage. Firstly, PAN co-VA copolymer is fed, in the form of pellets directly into the hopper. The pellets undergo melting and begin flow in the screw extruder leaving the exit gate.

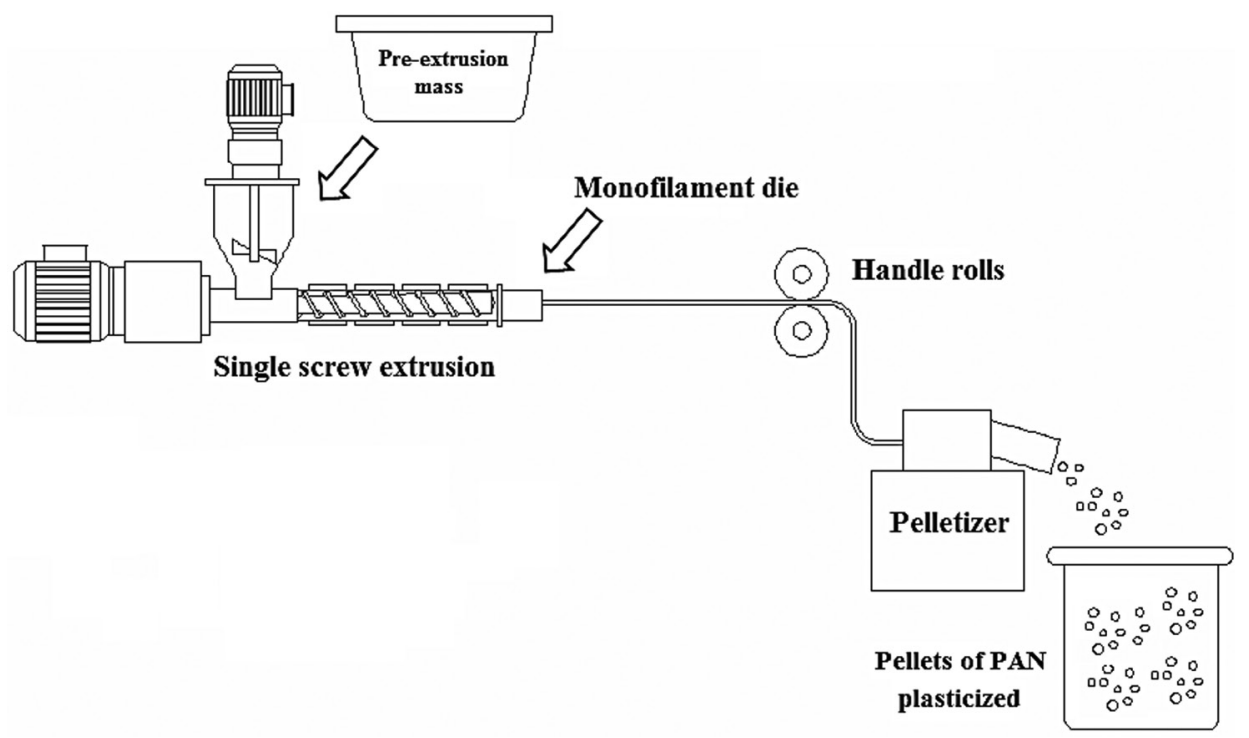

Figure 1. Schematic view of a single screw extruder for obtaining pellets of plasticized PAN. 
Afterwards, the molten PAN die drops by gravity into the cavity of a secondary extruder. The release of undesirable volatiles occurs during this event, avoiding wasting material, as occurred in the degassing of the single screw type extruder. Due to the strong backpressure generated in the die output, part of PAN melting run off by degassing orifice (area of lower pressure). The die output of spinning is coupled to the secondary extruder and the filaments emerging from the spinneret are directed by a guide cylinder to the roller guides. A hot air box chamber, working at $170{ }^{\circ} \mathrm{C}$, is positioned just after the spinning die and solidification of PAN fiber takes place by fast cooling.

\subsection{Thermal treatment}

Thermal stabilization of the extruded PAN fibers was carried out in a furnace under stagnated air atmosphere. No stretching was applied to the fiber material. The treatment temperature were set at $200^{\circ} \mathrm{C}, 220^{\circ} \mathrm{C}, 240^{\circ} \mathrm{C}$ and $260^{\circ} \mathrm{C}$. At each temperature, an isotherm treatment was performed at $30 \mathrm{~min}, 60 \mathrm{~min}$ and $90 \mathrm{~min}$. Heat treatments above $260^{\circ} \mathrm{C}$ were not possible to be done, because the fibers showed abrupt shrinkage leading to rupture.

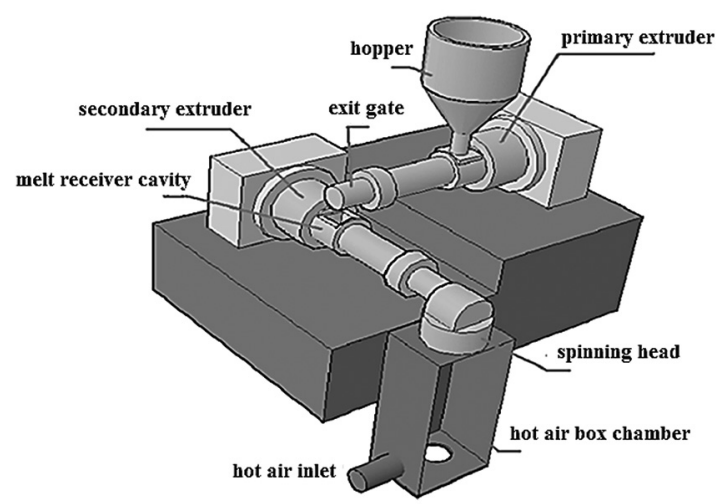

Figure 2. Schematic view of the cascade extruder for PAN fibers.

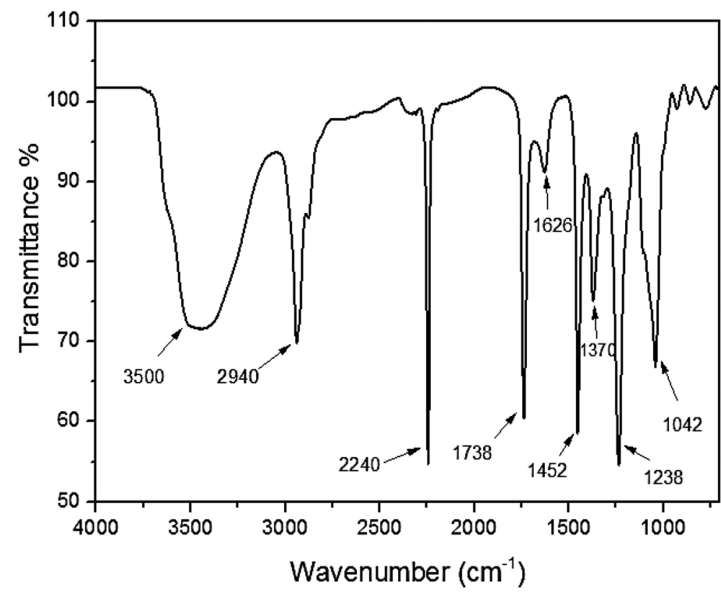

(a)

\subsection{Characterization}

FT-IR spectra of untreated PAN fibers were obtained on the Perkin Elmer, Spotlight 400 FTIR Imaging System model spectrometer. For the heat treated PAN fibers a FT-IR Pike Technologies Varian 640-IR model spectrometer was used. Both analyses were performed by ATR method in $4000-560 \mathrm{~cm}^{-1}$ range at $4 \mathrm{~cm}^{-1}$ resolution and 10 scans

Cross section fracture morphologies from the extruded PAN fibers were obtained by using LEO 435 Vpi scanning electron microscope. The samples were vacuum metalized with a thin film of gold-palladium alloy. The analysis was performed using $20 \mathrm{kV}$.

Thermogravimetric Analysis (TGA) and Differential Scanning Calorimetry (DSC) were performed to evaluate the thermal behavior of the extruded PAN fibers. TGA and DSC analysis were performed in a Shimadzu equipment model. The samples were placed in aluminum pan, with mass of $6.5 \mathrm{mg}$. The samples were heated from ambient temperature up to $350{ }^{\circ} \mathrm{C}$, at a heating rate of $5{ }^{\circ} \mathrm{C} / \mathrm{min}$. All the scans were performed in duplicate, under synthetic air and nitrogen flowing at $100 \mathrm{~mL} / \mathrm{min}$.

\section{Results and Discussion}

\section{1 FT-IR analysis}

The FT-IR spectra of the extruded PAN fibers are show in Figure 3a. The main chemical group assignments for the extruded PAN fibers were identify and have the same polymeric structure of the PAN fibers obtained by wet and dry spinning process. Of particular interest is the assignment at $2240 \mathrm{~cm}^{-1}$ which is attributed to the $\mathrm{C} \equiv \mathrm{N}$ stretching of acrylonitrile unit in the polymer chain and the bands at $2940 \mathrm{~cm}^{-1}\left(v_{\mathrm{C}-\mathrm{H}}\right.$ in $\left.\mathrm{CH}_{2}\right), 1452 \mathrm{~cm}^{-1}\left(\delta_{\mathrm{C}-\mathrm{H}}\right.$ in $\left.\mathrm{CH}_{2}\right)$ and $1370 \mathrm{~cm}-1\left(\delta_{\mathrm{C}-\mathrm{H}}\right.$ in $\left.\mathrm{CH}\right)$, which are characteristics of aliphatic $\mathrm{CH}$ groups along the PAN backbone ${ }^{[17,18]}$. The weak absorption at $1626 \mathrm{~cm}-1$ may be attributed to $\mathrm{C}=\mathrm{C}\left(\mathrm{v}_{\mathrm{C}=\mathrm{C}}\right)^{[19]}$.

A strong assignment appears at $1738 \mathrm{~cm}^{-1}$ which is attributed to the carbonyl group $(\mathrm{C}=\mathrm{O})$ stretching, which is due to the

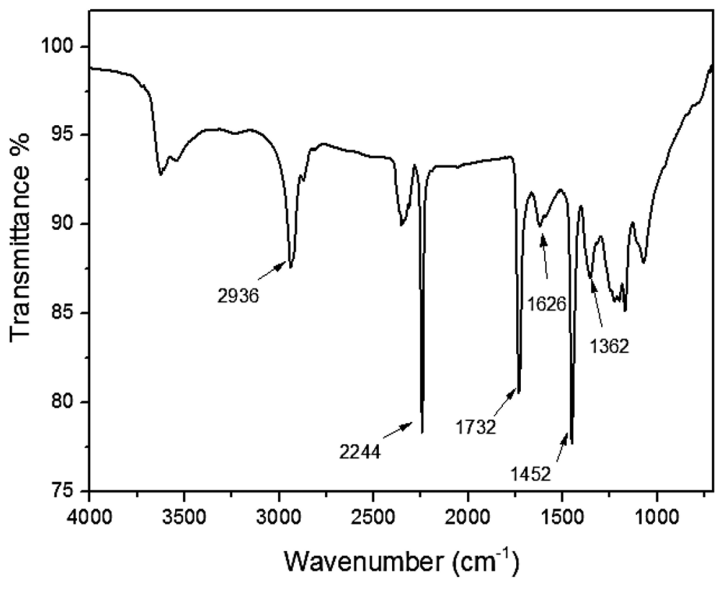

(b)

Figure 3. FT-IR spectra of (a) extruded PAN co-VA fibers and (b) commercial PAN co VA fibers obtained by wet spinning process having composition of $94 \% /$ mass of $\mathrm{AN}$ and $6 \% /$ mass of VA. 
ester and acids comonomers used in the polymerization of the PAN polymer. Ouyang ${ }^{[17]}$, Mathur ${ }^{[20]}$ and Wangxi ${ }^{[21]}$, also found an evident assignment of the carbonyl group of great intensity in PAN fiber copolymerized with itaconic acid and vinyl acetate, using IR technique.

Besides the carbonyl band, an intense assignment at $1238 \mathrm{~cm}^{-1}\left(v_{\mathrm{C}-\mathrm{O}}\right)$ is found which is related to the acetate group due to the vinyl acetate copolymer used in the synthesis of the PAN co-AV. At $1042 \mathrm{~cm}^{-1}$ another strong band appears assigned to the 1,2,3-propanetriol, used as a plasticizer during the PAN fiber spinning. This assignment band characterizes the $\mathrm{C}-\mathrm{O}$ groups, linked to the primary carbons of the 1,2,3-propanetriol. The broad band around $3500 \mathrm{~cm}^{-1}$ is a characteristic band of $\mathrm{O}-\mathrm{H}$ vibrations, which can be assigned to $\mathrm{O}-\mathrm{H}$ of the 1,2,3-propanetriol, as well as for $\mathrm{O}-\mathrm{H}$ from absorbed water in the fiber surface.

For comparison, a similar FT-IR ATR spectrum was obtained from a commercial PAN fiber having the same copolymer composition ( $94 \% \mathrm{AN} / 6 \% \mathrm{VA}$ ), but using the process of wet spinning with DMF solvent. It can be seen from Figure 3b, that the bands at $2936 \mathrm{~cm}^{-1}\left(v_{\mathrm{C}-\mathrm{H}}\right.$ in $\left.\mathrm{CH}_{2}\right)$, $1452 \mathrm{~cm}^{-1}\left(\delta_{\mathrm{CH}}\right.$ in $\left.\mathrm{CH}_{2}\right), 1362 \mathrm{~cm}^{-1}\left(\delta_{\mathrm{C}-\mathrm{H}}\right.$ in $\left.\mathrm{CH}\right), 2244 \mathrm{~cm}^{-1}$ $\left(v_{\mathrm{C}=\mathrm{N}}\right), 1626 \mathrm{~cm}^{-1}\left(v_{\mathrm{C}=\mathrm{C}}\right)$ and $1732 \mathrm{~cm}^{-1}\left(v_{\mathrm{C}=\mathrm{O}}\right)$, which are characteristic bands of PAN co-VA backbone, are similar to the assignment bands obtained for PAN fibers by obtained by the extrusion process showed in Figure 3a.

\subsection{Fracture morphology of PAN co-VA fibers}

The fundamental fiber structure needed to develop high strength must be created during the initial fiber formation step. The Figures 4 and 5 exhibits the SEM images of cross section and longitudinal section of the extruded PAN co-VA fibers, respectively. It can be observed from Figure 4 that the extruded PAN co-VA fibers exhibit a regular round cross section. This circular cross section is a result from the melted PAN co-VA copolymer extruded through the spinneret capillaries. A regular round cross section is the most appropriate morphology for the thermal conversion process to high performance carbon fibers, because it provides a homogeneous shrinkage and mass reduction, keeping other process parameter under control, throughout the fiber during the thermal treatment cycle. Regular round cross section and strict heat treatment process control reduces the probability of defects that may affect the final mechanical properties of the carbon fibers.

The magnified image from Figure 4 shows the cross section of the PAN co-VA where voids can be seen, as

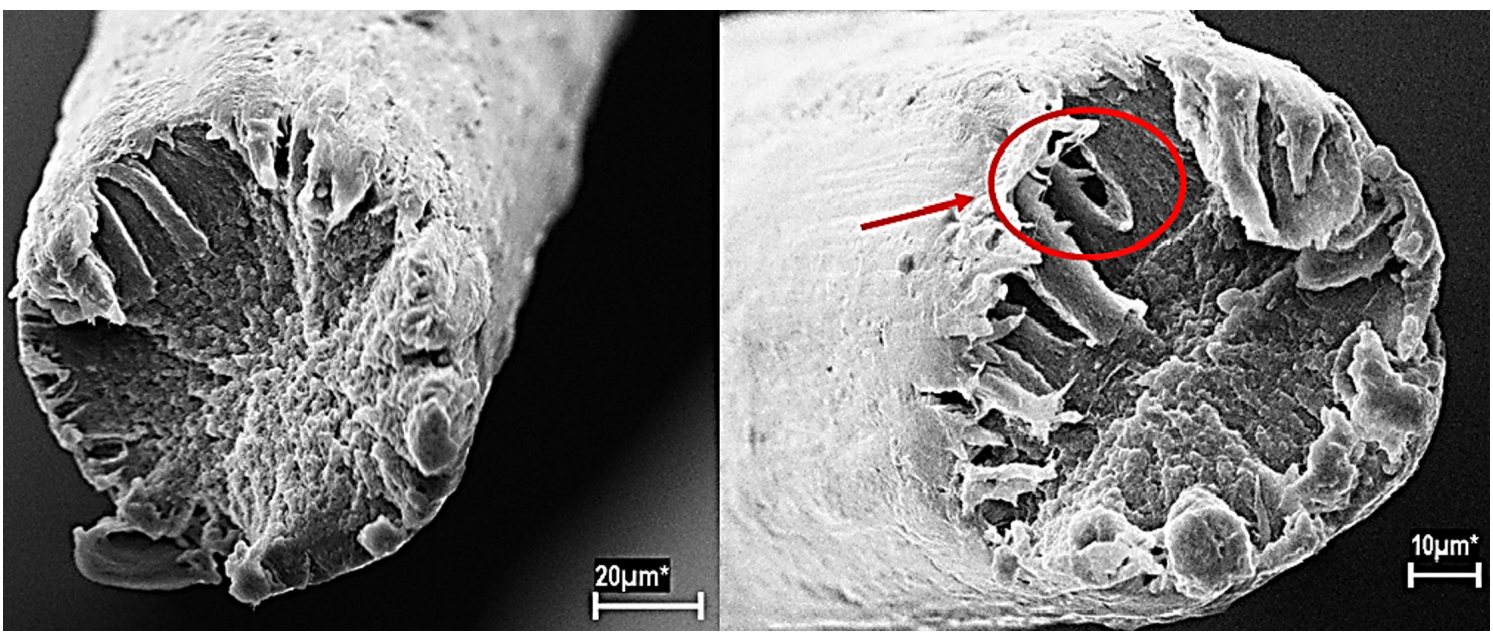

Figure 4. Cross section SEM images of fracture morphologies of extruded PAN co-VA fibers.

(a)

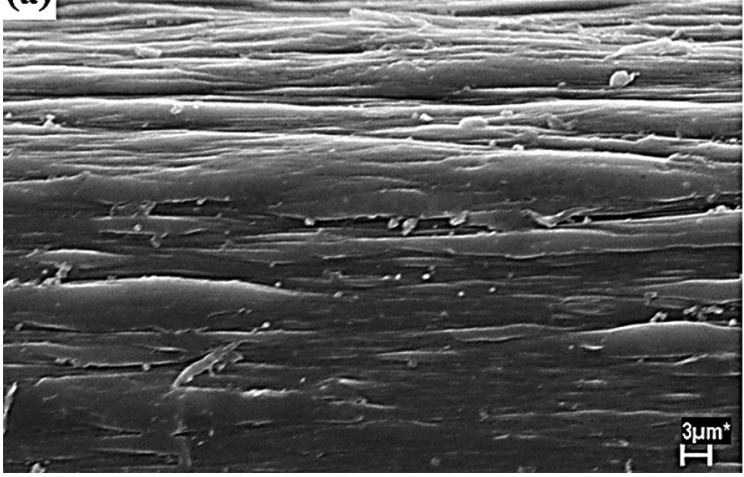

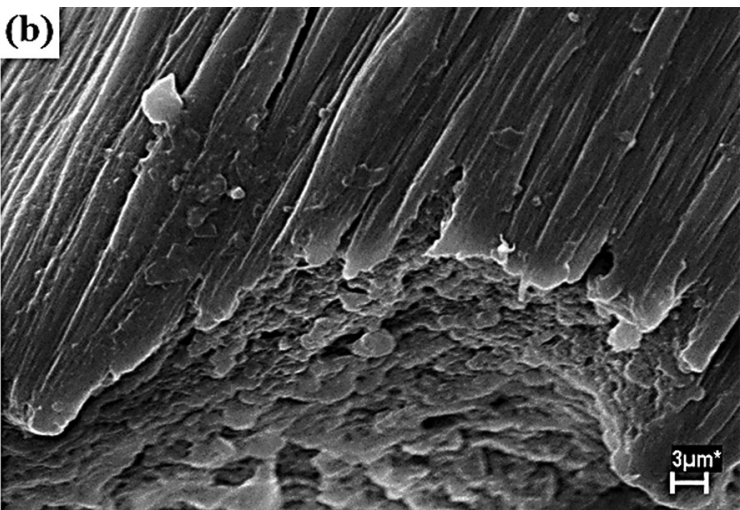

Figure 5. Longitudinal section SEM morphology images of extruded PAN co-VA fibers, showing longitudinal polymer fibrils (a) and polymer granules at the core of the fiber (b). 
indicated by the red circle. In this case, the release of plasticizer during extrusion can be the source of such defects. Voids are harmful and undesirable since they compromise the tensile fracture of the precursor fiber. According to $\mathrm{Ji}^{[23]}$, voids are stress concentrators and a source of the tensile fracture. Efforts in the process to obtain carbon fibers are addressed to reduce the number and the size of voids, and so a high tensile strength can be obtained.

Figure 5a shows a longitudinal surface view of the extruded PAN co-VA fibers. The polymer fibrils are oriented preferably in the direction parallel to the longitudinal axis of the fiber. This is due to the fact that extrusion process orients the molecular chains of the PAN co-VA polymer longitudinally during spinning even before the drawing step.

The image from Figure 5a shows that granules showed in Figure 5b are the fracture ends of fibrils and the transverse section of these granules are randomly distributed. Chain-like molecules present when PAN polymer are spun is a well-known morphology present in fiber precursors for carbon fibers, which indicates an adequate orientation in the axial direction. Besides, a random distribution of the fiber ends granules in the transverse direction results in a random transverse texture ${ }^{[22,23]}$.

\subsection{Thermogravimetric Analysis (TGA)}

The evolution of weight loss of the extruded PAN co-VA fibers was measured as a function of temperature under oxidative atmosphere and under inert atmosphere, as shown in Figures $6 \mathrm{a}$ and $6 \mathrm{~b}$, respectively. Main oxidative reactions from the thermal stabilization stage of these fibers takes place up to $350{ }^{\circ} \mathrm{C}^{[2,24]}$.

The curves shown in Figure 6 shows that extruded PAN co-VA fibers exhibits three characteristic regions of weight loss. The weight loss of PAN co-VA fibers under oxidizing atmosphere shows a weight loss of $\sim 8 \%$, and under inert atmosphere the weight loss is $\sim 6 \%$, up to $\sim 110{ }^{\circ} \mathrm{C}$. These levels of weight loss are attributed to adsorbed humidity, in addition to the release of 1,2,3-propanetriol, used as a plasticizer during fiber spinning. The presence of humidity and 1,2,3-propanetriol can also be demonstrated by free $\mathrm{OH}$ characteristic assignment detected in the FT-IR analysis, as showed the Figure $3 \mathrm{a}$.

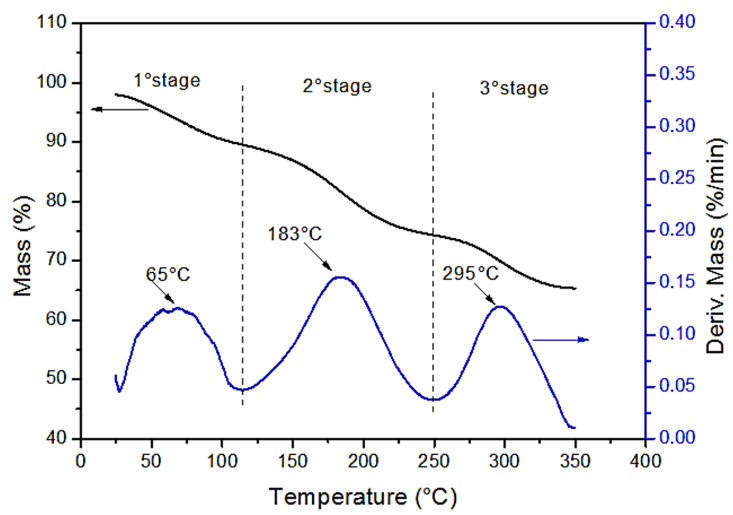

(a)
The second stage of weight loss is in the temperature range of $125{ }^{\circ} \mathrm{C}$ to $250{ }^{\circ} \mathrm{C}$, which corresponds to a $15 \%$ weight loss for both samples analyzed under oxidizing atmosphere and inert atmosphere. In this case, weight loss can be attributed to dehydrogenation reactions and release of gases, such as $\mathrm{CO}_{2}{ }^{[25]}$.

The third step, between $250{ }^{\circ} \mathrm{C}$ and $350{ }^{\circ} \mathrm{C}$, corresponds to a $9 \%$ weight loss to samples analyzed under oxidizing atmosphere. On the other hand, when the samples were analyzed under inert atmosphere the weight loss $(\sim 18 \%)$ is more significant compared to the analysis showed in Figure 6(a), which is approximately twice the weight loss measured under oxidizing atmosphere. Thus, the yield on carbon from extruded Pan co-VA fiber under inert atmosphere is smaller than the resulted yield measured under oxidizing atmosphere. Anyway, in both samples, the weight loss can be attributed to the release of volatiles, such as $\mathrm{H}_{2} \mathrm{O}, \mathrm{CO}$, $\mathrm{CO}_{2}, \mathrm{CH}_{4}, \mathrm{NH}_{3}$ and $\mathrm{HCN}^{[25,26]}$.

As a matter of fact, under oxidizing atmosphere, the extruded PAN co-VA fibers exhibit a gradual weight loss. From $250{ }^{\circ} \mathrm{C}$ to $350{ }^{\circ} \mathrm{C}$ the oxidation reactions occur with greater intensity and acting as a dehydrogenation agent during the conversion of $\mathrm{C}-\mathrm{C}$ bonds to $\mathrm{C}=\mathrm{C}$ bonds. Oxygen molecules also generate oxygen-bearing groups in the polymer backbone, such as $\mathrm{OH}, \mathrm{C}=\mathrm{O}$ and $\mathrm{COOH}$. These groups promote intermolecular crosslinking of the polymer chains and provide greater stability to sustain high temperature carbonization treatment ${ }^{[17,18]}$.

The formations of ammonia and hydrogen cyanide have been reported by several workers but nobody has suggested a detailed pathway for these reactions, especially in the absence of oxygen ${ }^{[27]}$. According to Xue ${ }^{[27]}$, the formation of $\mathrm{NH}_{3}$ is assumed to be due to the terminal imine group from the cyclized structure and the formation of $\mathrm{HCN}$ is assumed to be due to the uncyclized nitrile group.

The analysis carried out in the extruded PAN co-VA fiber under inert atmosphere favors a loss in properties because a non-stable structure is prone to oxygen attack. The yield of carbon after heat treatment schedule of a precursor fiber is a key issue in the carbon fiber manufacture. If the carbon yield is low, the tensile strength and elastic modulus will tend to exhibit lower values ${ }^{[2]}$. This means that heat treatment

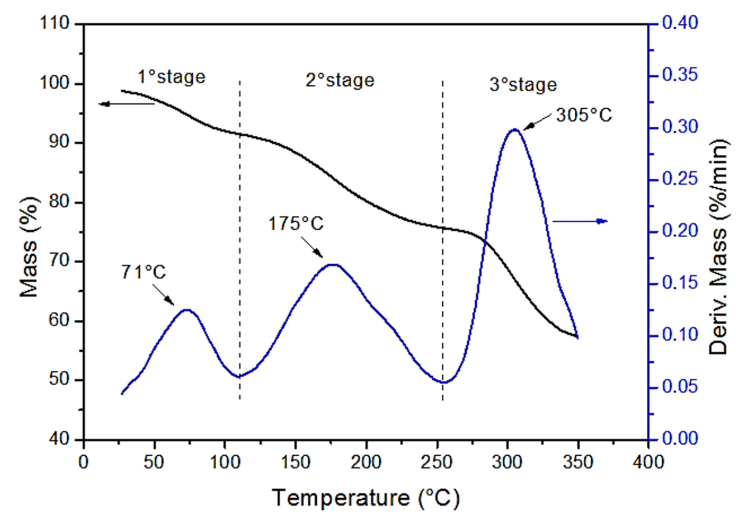

(b)

Figure 6. TGA curve of the extruder PAN co-VA fibers heated at $5{ }^{\circ} \mathrm{C} / \mathrm{min}$ under (a) oxidizing atmosphere and (b) inert atmosphere. 
of PAN co-VA under oxidizing atmosphere is convenient during the stabilization process in order to get carbon fibers with better properties.

\subsection{Differential Scanning Calorimetry (DSC)}

The Figure 7 shows a DSC analysis where an exothermic thermal event occurs, related to the extruded PAN co-VA fibers stabilization stage, under oxidizing synthetic air atmosphere and inert atmosphere. In general, exothermic events occurring on polyacrylonitrile polymer, takes place owing to the cyclization reactions of nitrile groups, dehydrogenation, crosslinking and oxidative reactions, when treatment is performed at oxidizing atmosphere ${ }^{[14,19]}$.

The exothermic reactions occurring on the extruded PAN co-VA fibers initiate at $\sim 190^{\circ} \mathrm{C}\left(\mathrm{T}_{\mathrm{i}}\right)$, goes to a peak at $290^{\circ} \mathrm{C}$ and ended at $\sim 340{ }^{\circ} \mathrm{C}\left(\mathrm{T}_{\mathrm{f}}\right)$. The extent of the stabilization event $\left(\Delta \mathrm{T}=\mathrm{T}_{\mathrm{f}}-\mathrm{T}_{\mathrm{i}}\right)$, under oxidizing atmosphere, is around $150{ }^{\circ} \mathrm{C}$ and releases an amount of energy of about $93 \mathrm{~J} / \mathrm{g}$. Under inert nitrogen flow atmosphere the exothermic reactions initiate about $195^{\circ} \mathrm{C}\left(\mathrm{T}_{\mathrm{i}}\right)$, having a peak at $297^{\circ} \mathrm{C}$ and ended about $318^{\circ} \mathrm{C}\left(\mathrm{T}_{\mathrm{f}}\right)$. The extent of the stabilization

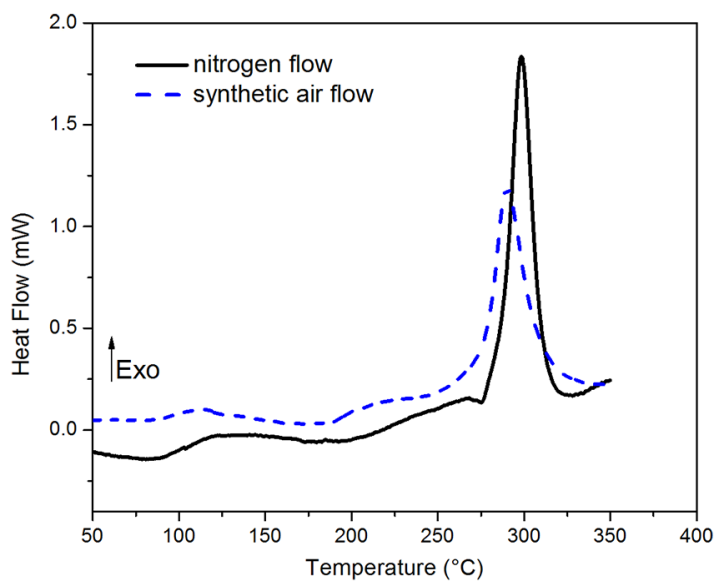

Figure 7. DSC curves of extruder PAN co-VA fibers heated $5{ }^{\circ} \mathrm{C} /$ min under synthetic air flow and nitrogen flow.

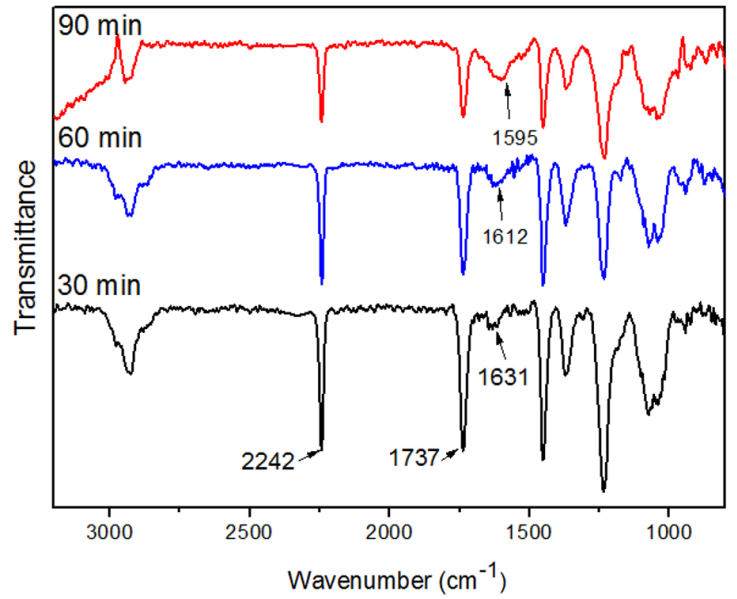

(a) event $\left(\Delta \mathrm{T}=\mathrm{T}_{\mathrm{f}}-\mathrm{T}_{\mathrm{i}}\right)$, under inert atmosphere, is around $123{ }^{\circ} \mathrm{C}$ and releases an amount of energy about $70 \mathrm{~J} / \mathrm{g}$. It is observed that under inert nitrogen atmosphere the reaction exhibits a short extension $\left(\Delta \mathrm{T}=\mathrm{T}_{\mathrm{f}}-\mathrm{T}_{\mathrm{i}}\right)$ and peaks of higher magnitude and narrower are present. Thus, under inert atmosphere, the exothermic reactions release energy in a shorter time interval, the weight loss rate is increased and further reaction may become uncontrolled. This can be attributed to the lack of crosslinking generated by oxygen groups in the polymer backbone.

DSC results showed that extruded PAN co-VA fibers analysed under oxidizing and inert atmosphere have a main thermal event in the temperature range of $180{ }^{\circ} \mathrm{C}$ to $350{ }^{\circ} \mathrm{C}$, which is in accordance with the temperature range for exothermic reactions related to the thermal stabilization step of PAN based carbon fibers. Other studies that evaluated PAN fibers spun by the wet and dry spinning process, using solvents such as DMSO and DMF, also found similar results ${ }^{[28,29]}$.

\subsection{FT-IR analysis of the PAN co-VA fibers heat treated at different temperatures and times}

Figures 8 and 9 shows FT-IR spectra from extruded PAN co-VA fibers heat treated at different temperatures and times. It is observed, as shown in Figure 8a, that the PAN fibers heat treated at $200{ }^{\circ} \mathrm{C}$ for $30 \mathrm{~min}$ shows peak assignments similar to the spectrum of the untreated PAN fibers. However, an increase in the dwell time at $200^{\circ} \mathrm{C}$, leads the weak band at $1631 \mathrm{~cm}^{-1}$, assigned to the stretching $\mathrm{C}=\mathrm{C}$, being moved for a new assignment band around $1595 \mathrm{~cm}^{-1}$. According to Rahaman ${ }^{[13]}$ and Ouyang ${ }^{[17]}$, this weak band at $1595 \mathrm{~cm}^{-1}$ seems to be due to a combination of vibrations of $\mathrm{C}=\mathrm{C}$ and $\mathrm{C}=\mathrm{N}$ stretching, and $=\mathrm{N}-\mathrm{H}$ in-plane bending of the ladder frame structure of the stabilized PAN. This results in the progress of cyclization and dehydrogenation of PAN fibers, as can be confirmed by DSC curve (Figure 7), which shows at $200{ }^{\circ} \mathrm{C}$ the beginning of the thermal event.

Heat treatment of PAN co-VA fiber at $220{ }^{\circ} \mathrm{C}$ shows a characteristic assignment band, related to the cyclization, between $1590 \mathrm{~cm}^{-1}$ and $1596 \mathrm{~cm}^{-1}$ which is more intense.

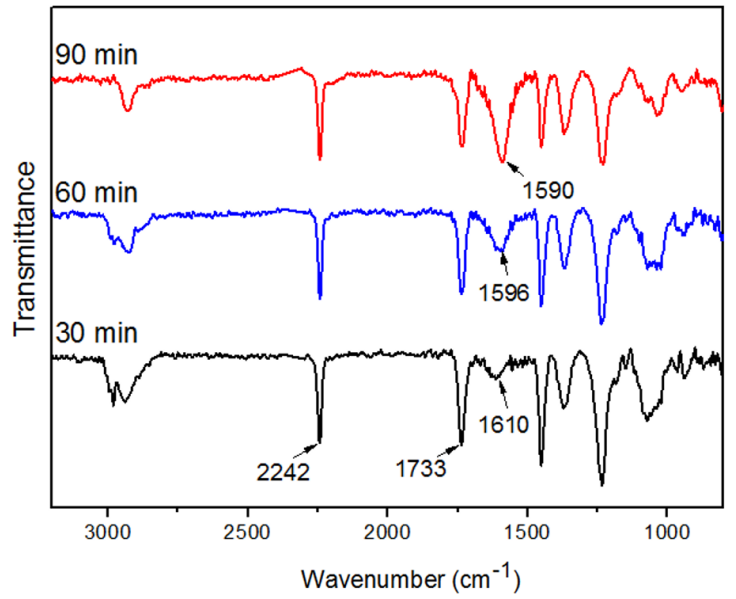

(b)

Figure 8. FT-IR spectra of extruder PAN co-VA fibers heated at (a) $200{ }^{\circ} \mathrm{C}$ and (b) $220{ }^{\circ} \mathrm{C}$, for different times. 


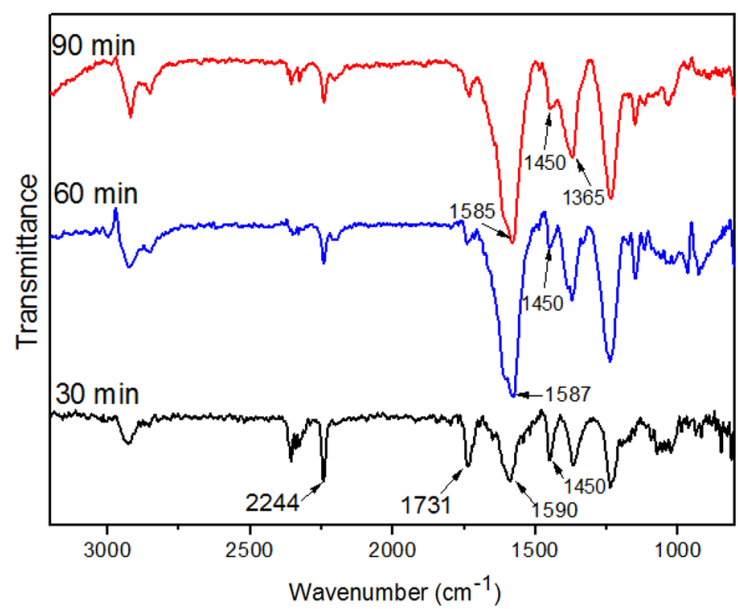

(a)

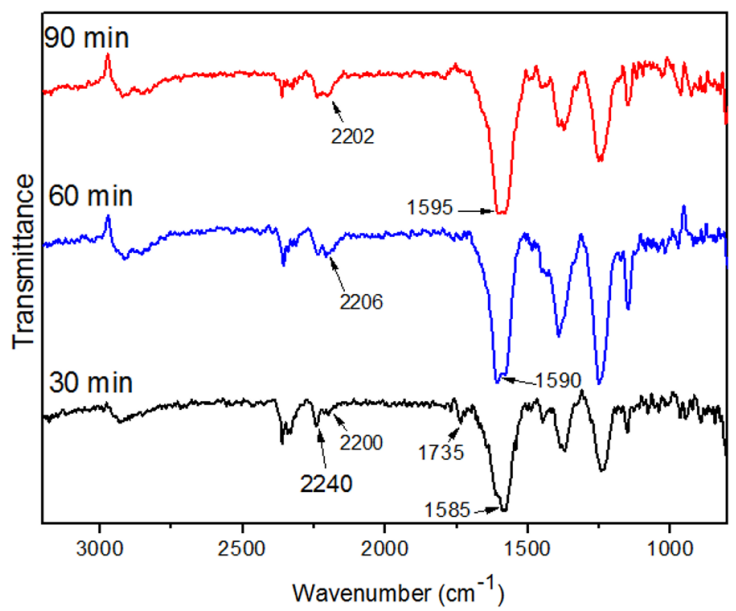

(b)

Figure 9. FT-IR spectra of extruder PAN co-VA fibers heated at (a) $240{ }^{\circ} \mathrm{C}$ and (b) $260{ }^{\circ} \mathrm{C}$, for different times.

After 90 min treatment at $220^{\circ} \mathrm{C}$, as shown in Figure $8 \mathrm{~b}$, the cyclization assignment band $\left(1590 \mathrm{~cm}^{-1}\right)$ finally overtakes the $2242 \mathrm{~cm}^{-1}$ band.

It is observed, according to Figure $9 \mathrm{a}$, that after $30 \mathrm{~min}$ treatment at $240{ }^{\circ} \mathrm{C}$, the $2244 \mathrm{~cm}^{-1}$ assignment band related to the nitrile groups shows a significant decrease in intensity. Concomitantly, the band corresponding to cyclization $\left(1590 \mathrm{~cm}^{-1}\right)$ continues to increase, becoming very strong. Besides, it is interesting to observe that the assignment band at $1450 \mathrm{~cm}^{-1}$, which is attributed to the $\mathrm{C}-\mathrm{H}$ in $\left(-\mathrm{CH}_{2}\right)$ bending, begins to decrease in intensity becoming a shoulder of the $1365 \mathrm{~cm}^{-1}$ band, which assigned to the $\mathrm{C}-\mathrm{H}$ in $(-\mathrm{CH})$ bending. This result shows that during the dehydrogenation reactions, the hydrogen atoms linked in $\left(-\mathrm{CH}_{2}\right)$ are broken more frequently.

When heat treatment of extruded PAN co-VA fibers are performed at $260{ }^{\circ} \mathrm{C}$, a weak band appears around $2200 \mathrm{~cm}^{-1}$. This band was suggested to be assigned to the unsaturated nitrile groups arose from dehydrogenation, or from tautomerization of the ladder polymer ${ }^{[17,19]}$. The PAN fibers heat treatment at $260{ }^{\circ} \mathrm{C}$ for $90 \mathrm{~min}$ still shows a weak band at $2240 \mathrm{~cm}^{-1}$ which indicates that a small fraction of nitrile groups fails to complete the cyclization.

According to Mathur ${ }^{[20]}$, the characteristic band that gives evidence of the presence of the vinyl acetate unit in the AN/VA copolymer is the carbonyl band, around $1730 \mathrm{~cm}^{-1}$. This band appears with great intensity in the untreated PAN co-VA fibers, studied in the present work. But, as shown in Figure 9a, this band begins to decrease in intensity after $30 \mathrm{~min}$ at $240{ }^{\circ} \mathrm{C}$, and almost disappears after $60 \mathrm{~min}$ of treatment. In the spectrum of the Figure $9 \mathrm{~b}$ the carbonyl band is vanished. These results show that the oxygen did not generate groups as $\mathrm{C}=\mathrm{O}$ in the polymer back-bone.

\section{Conclusions}

PAN co-VA fiber was obtained by conventional extruder process. This process (melt spinning) converted a pure precursor directly into fiber form and not involved the added expense of solvent.
The FT-IR analysis results showed that PAN co-VA fibers, obtained by extrusion process, exhibited the main functional groups, similar to the ones founded from other PAN fibers obtained by wet and dry spinning.

The thermal analysis (TGA and DSC) showed that stabilization stage of the PAN co-VA fibers beyond to being consistent with other fibers obtained by wet and dry spinning process, when it was performed in an oxidizing atmosphere showed a more stable release of volatiles, allowing a higher yield of carbon.

\section{Acknowledgements}

We thank the Quimlab Company for the viability of the present work and CNPq for the financial support.

\section{References}

1. Masson, J. C. (1995). Acrylic fiber technology and applications. New York: Marcel Dekker.

2. Morgan, P. E. (2005). Carbon fibers and their composites. Boca Raton: CRC Press. http://dx.doi.org/10.1201/9781420028744.

3. Edie, D. D. (1998). The effect of processing on the structure and properties of carbon fibers. Carbon, 36(4), 345-362. http:// dx.doi.org/10.1016/S0008-6223(97)00185-1.

4. Brito, C. A. R., Jr., Fleming, R. R., Pardini, L. C., \& Alves, N. P. (2013). Poliacrilonitrila: processos de fiação empregados na indústria. Polímeros: Ciência e Tecnologia, 23(6), 764-770. http://dx.doi.org/10.4322/polimeros.2013.006.

5. Blickenstaff, R. A. (1976). US Patent 3984601. United States. Retrieved in 22 September 2014, from https://www.google. com.ar/patents/US3984601.

6. Yoon, H. S. (1995). US Patent 5434002. United States. Retrieved in 22 September 2014, from http://www.google. com.py/patents/US5434002.

7. Yoon, H. S. (1996). US Patent 5589264. United States.Retrieved in 22 September 2014, from http://www.google.com/patents/ US5589264.

8. Smierciak, R. C. (1997). US Patent 5602222. United States. Retrieved in 22 September 2014, from https://www.google. com.ar/patents/US5602222. 
9. Smierciak, R. C. (1997). US Patent 5618901. United States. Retrieved in 22 September 2014, from https://www.google. com.ar/patents/US5618901.

10. Bortner, M. J. (2003). Melt processing of metastable acrylic copolymer carbon precursors (Doctoral thesis). Virginia Polytechnic Institute, Blacksburg.

11. Alves, N. P. (2007). WO Patent 147224 A2. Patent Cooperation Treaty. Retrieved in 22 September 2014, from http://www. google.com/patents/WO2007147224A2?cl=en

12. Brito Júnior, C. A. R., Fleming, R. R., Pardini, L. C., \& Alves, N. P. (2012). Análise térmica da poliacrilonitrila plastificada com glicerol em extrusora. Polímeros: Ciência e Tecnologia, 22(4), 364-368. http://dx.doi.org/10.1590/S0104-14282012005000055.

13. Rahaman, M. S. A., Ismail, A. F., \& Mustafa, A. (2007). A review of heat treatment on polyacrylonitrile fiber. Polymer Degradation \& Stability, 92(8), 1421-1432. http://dx.doi. org/10.1016/j.polymdegradstab.2007.03.023.

14. Furushima, Y., Nakada, M., Takahashi, H., \& Ishikiriyama, K. (2014). Study of melting and crystallization behavior of polyacrylonitrile using ultrafast differential scanning calorimetry. Polymer, 55(13), 3075-3081. http://dx.doi.org/10.1016/j. polymer.2014.05.015.

15. Sedghi, A., Farsani, R. E., \& Shokuhfar, A. (2008). The effect of commercial polyacrylonitrile fibers characterizations on the produced carbon fibers properties. Journal of Materials Processing Technology, 198(1-3), 60-67. http://dx.doi. org/10.1016/j.jmatprotec.2007.06.052.

16. Xue, Y., Liu, J., \& Liang, J. (2013). Correlative study of critical reactions in polyacrylonitrile based carbon fiber precursors during thermal-oxidative stabilization. Polymer Degradation \& Stability, 98(1), 219-229. http://dx.doi.org/10.1016/j. polymdegradstab.2012.10.018.

17. Ouyang, Q., Cheng, L., Wang, H., \& Li, K. (2008). Mechanism and kinetics of the stabilization reactions of itaconic acid-modified polyacrylonitrile. Polymer Degradation \& Stability, 93(8), 14151421. http://dx.doi.org/10.1016/j.polymdegradstab.2008.05.021.

18. Arbab, S., \& Zeinolebadi, A. (2013). A procedure for precise determination of thermal stabilization reactions in carbon fiber precursors. Polymer Degradation \& Stability, 98(12), 2537-2545. http://dx.doi.org/10.1016/j.polymdegradstab.2013.09.014.

19. Ju, A., Guang, S., \& Xu, H. (2013). Effect of comonomer structure on the stabilization and spinnability of polyacrylonitrile copolymers. Carbon, 54, 323-335. http://dx.doi.org/10.1016/j. carbon.2012.11.044.
20. Mathur, R. B., Bahl, O. P., \& Sivaram, P. (1992). Thermal degradation of polyacrilonitrile fibres. Current Science, 62(10), 662-669.

21. Wangxi, Z., Jie, L., \& Gang, W. (2003). Evolution of structure and properties of PAN precursors during their conversion to carbon fibers. Carbon, 41(14), 2805-2812. http://dx.doi. org/10.1016/S0008-6223(03)00391-9.

22. Ji, M., Wang, C., Bai, Y., Yu, M., \& Wang, Y. (2007). Comparison of tensile fracture morphologies among various polyacrylonitrile-based carbon fibers. Polymer Bulletin, 59(3), 381-390. http://dx.doi.org/10.1007/s00289-007-0773-x.

23. Ji, M., Wang, C., Bai, Y., Yu, M., \& Wang, Y. (2007). Structural evolution of polyacrylonitrile precursor fibers during preoxidation and carbonization. Polymer Bulletin, 59(4), 527-536. http:// dx.doi.org/10.1007/s00289-007-0796-3.

24. Kalashnik, A. T. (2002). The role of different factors in creation of the structure of stabilized acrylic fibres. Fibre Chemistry, 34(1), 10-17. http://dx.doi.org/10.1023/A:1015595021817.

25. Wu, G. P., Lu, C. X., Ling, L. C., \& Lu, Y. G. (2009). Comparative investigation on the thermal degradation and stabilization of carbon fiber precursors. Polymer Bulletin, 62(5), 667-678. http://dx.doi.org/10.1007/s00289-009-0039-x.

26. Nielsen, M., Jurasek, P., Hayashi, J., \& Furimsky, E. (1995). Formation of toxic gases during pyrolysis of polyacrylonitrile and nylons. Journal of Analytical and Applied Pyrolysis, 35(1), 43-51. http://dx.doi.org/10.1016/0165-2370(95)00898-O.

27. Xue, T. J., Mckinney, M. A., \& Wilkie, C. A. (1997). The thermal degradation of polyacrylonitrile. Polymer Degradation \& Stability, 58(1-2), 193-202. http://dx.doi.org/10.1016/S01413910(97)00048-7.

28. Zhang, W., \& Li, M. (2005). DSC study on the polyacrylonitrile precursors for carbon fibers. Journal of Materials Science and Technology, 21(4), 581-584. Retrieved in 22 September 2014, from http://www.jmst.org/fileup/PDF/2004258.pdf

29. Ouyang, Q., Cheng, L., Wang, H. J., \& Li, K. X. (2008). DSC study of stabilization reaction in poly (Acrylonitrileco-Itaconic Acid) with Peak-Resolving method. Journal of Thermal Analysis and Calorimetry, 94(1), 85-88. http://dx.doi. org/10.1007/s10973-007-8773-5.

Received: Sept. 22, 2014

Revised: Mar. 23, 2015

Accepted: June 19, 2015 